\title{
Non-cell autonomous induction of apoptosis and loss of posterior structures by activation domain-specific interactions of Oct-1 in the Xenopus embryo
}

Gert Jan C. Veenstra ${ }^{1,4}$, Joselin Peterson-Maduro', Marco Th. Mathu ${ }^{1}$, Peter C. van der Vliet ${ }^{2}$ and Olivier H.J. Destrée ${ }^{1,3}$

${ }^{1}$ Hubrecht Laboratory, Netherlands Institute for Developmental Biology, Uppsalalaan 8, 3584 CT Utrecht, The Netherlands

${ }^{2}$ Laboratory for Physiological Chemistry, Utrecht University, Utrecht, The Netherlands

${ }^{3}$ corresponding author: tel: +31 30 2510211; fax: +31 30 2516464; e-mail: olivier@niob.knaw.nl

${ }^{4}$ Present address: Laboratory for Molecular Embryology, NICHD, National Institutes of Health, Bethesda, Maryland 20892, USA

Received: 9.2.98; revised 10.4.98; accepted 18.5.98

Edited by R.A. Knight

\begin{abstract}
Oct-1, a member of the POU family of transcription factors, is expressed at relatively high levels in ectodermal and mesodermal cell lineages during early Xenopus embryogenesis (Veenstra et al, 1995). Here we show that overexpression of Oct-1 induces programmed cell death concomitant with the loss of the posterior part of the body axis. Truncated Oct-1 variants, missing either the $\mathrm{C}$-terminal or $\mathrm{N}$-terminal transactivation domain, exhibit a different capacity to cause such developmental defects. Oct-1-induced cell death is rescued in unilaterally injected embryos by non-injected cells, indicative of the non-cell autonomous character of the developmental effects of Oct-1. This was confirmed by marker gene analysis, which showed a significant decrease in brachyuryexpression, suggesting that Oct-1 interferes with an FGF-type signalling pathway.
\end{abstract}

Keywords: Oct-1; POU domain; apoptosis; FGF; Xenopus

Abbreviations: PCD, programmed cell death; TUNEL, Tdtmediated dUTP nick end labelling; PI, posterior-deleted index; $\mathrm{P}$, $\mathrm{POU}$ domain alone; $\mathrm{N}, \mathrm{N}$-terminal domain alone; $\mathrm{C}, \mathrm{C}$-terminal activation domain alone; EGT, early gastrula transition; MBT, midblastula transition; XFD, dominant-negative FGF receptor; TSH, thyrotropin; PBS, phosphate buffered saline

\section{Introduction}

The genetic programme that controls embryonic development relies on regulation by transcription factors. The majority of known transcription factors belongs to one of several large gene families that share a homologous DNA binding domain (Mitchell and Tjian, 1989; Harrison, 1991). One of the families of transcription factors implicated in development is that of the
POU proteins (Rosenfeld, 1991; Schöler, 1991; Verrijzer and Van der Vliet, 1993; Herr and Cleary, 1995; Veenstra et al, 1997). The common DNA binding motif of the family members, the POU domain, is subdivided in two subdomains, a POU-type homeodomain and a POU-specific domain. Both subdomains are indispensable for sequencespecific DNA-binding to the octamer motif ATGCAAAT, or closely related motifs (Verrijzer and Van der Vliet, 1993; Herr and Cleary, 1995).

Many POU factor genes show a temporally or spatially restricted expression during development $(\mathrm{He}$ et al, 1989; Hatzopoulos et al, 1990; Rosner et al, 1990; Suzuki et al, 1990; Agarwal and Sato, 1991; Frank and Harland, 1992; Whitfield et al, 1993). Functions during embryonic development have been established for three of the initially identified POU domain proteins (Herr et al, 1988), i.e. for Pit-1, Oct-2 and Unc-86 (Finney and Ruvkun, 1990; Corcoran et al, 1993; Andersen and Rosenfeld, 1994), as well as for a number of more recently identified POU domain transcription factors (Fujii and Hamada, 1993; Shimazaki et al, 1993; Takeda et al, 1994; Bhat et al, 1995; Nakai et al, 1995; Schonemann et al, 1995; Witta et al, 1995; Yeo et al, 1995). Pit-1 function appeared to be critical for expression of pituitary-specific effector genes and for proliferation or survival of three anterior pituitary cell types (reviewed by Anderson and Rosenfeld (1994)). Oct-2 proved to serve a critical function in B-cell maturation (Corcoran et al, 1993), and the unc-86 gene product is important for lineage-dependent neuronal specification (Finney and Ruvkun, 1990). The role of Oct-1 during development, however, has remained elusive. Oct-1 is widely (Staudt et al, 1986; Sturm et al, 1988; Schöler et al, 1989; Kambe et al, 1993), though differentially expressed during development (He et al, 1989; Veenstra et al, 1995) Relatively high levels of Oct- 1 protein are present in ectoderm and mesoderm of gastrula and neurula stage Xenopus embryos. During further development Oct-1 becomes progressively spatially restricted within the developing anterior central nervous system and in cranial neural crest derivatives (Veenstra et al, 1995).

Oct-1 contains several trans-activation domains that function in a promoter-selective fashion. The POU domain not only mediates sequence-specific binding to DNA, but provides surface-exposed interfaces for protein-protein interactions as well, and in some cases the POU domain suffices for transcriptional activation (Murphy et al, 1992; Tanaka et al, 1992; Luo and Roeder, 1995; Mittal et al, 1996). In addition, both the regions N-terminal and Cterminal of the Oct-1 POU domain exhibit trans-activation activity, but these domains are differentially active, dependent on promoter context (Tanaka and Herr, 1990; Tanaka et al, 1992). 
In this paper we report on the developmental defects caused by expression of full length Oct-1 and Oct-1 variants missing either the $\mathrm{C}$-terminal or the $\mathrm{N}$-terminal trans-activation domain, or both. We show that Oct-1 overexpression causes enhanced apoptosis in gastrulating Xenopus embryos, which is accompanied by the loss of posterior structures of the body axis. We have characterised the early spatio-temporal pattern of both endogenous and Oct-1-induced programmed cell death (PCD) in the amphibian embryo. The induced PCD appears to initiate concomitant with the appearance of endogenous apoptosis. In addition, the data indicate that both PCD and the loss of posterior structures are mediated by a non-cell autonomous mechanism, and marker gene analysis suggests that it involves impaired signalling of a member of the FGF-family of growth factors.

\section{Results \\ Oct-1 overexpression causes apoptosis and posterior deletions}

We previously reported the spatio-terminal distribution of Oct-1 RNA and Oct-1 protein during Xenopus embryogenesis, as a first step towards the elucidation of the role of this transcription factor (Veenstra et al, 1995). To test if altered expression of Oct-1 would disturb embryonic development, overexpression experiments were performed. Expression of full length Oct-1 by injection of in vitro synthesized capped RNA into zygotes perturbs embryonic development, starting at gastrulation, whereas injection of antisense control RNA has no effect. Development of Oct-1 overexpressing embryos is normal during cleavage stages. At gastrula stage 10, the dorsal blastopore lip is thicker and it slightly diverges from the yolk plug, resulting in a pit between the dorsal blastopore lip and the yolk plug. During subsequent development (Figure $1 \mathrm{~F}-\mathrm{H}$ ), the internal gastrulation movements are abnormal, the archenteron is absent (Figure 2C), and cells detach from the dorsal blastospore lip (Figures $2 \mathrm{C}$ and $3 A-B)$, which causes a cleft between the yolk plug and the dorsal blastospore lip. The embryos become covered by detached cells that accumulate within the vitelline membrane (Figures $1 \mathrm{H}, \mathrm{I}$ and $2 \mathrm{C}$ ), and continue developing until at least tadpole stages. Tail development however, is severely affected; in a significant proportion of injected embryos (see below) the tail is rudimentary (Figures $1 \mathrm{I}-\mathrm{K}$ and 2D). Development of the head and trunk is retarded, but the proportions and gross morphology of these structures is relatively normal in most embryos (Figure 2D). The minor abnormalities observed in the anterior part of the embryo during later development were either not fully penetrating or could easily represent indirect effects of earlier perturbations. Increasing the dose of injected RNA results in an increase of the number of dissociated cells, incidently but not typically leading to complete dissociation of the gastrula embryo and cessation of embryonic development.

The dissociated cells received and translated the injected RNA, which was assessed both by co-injection of

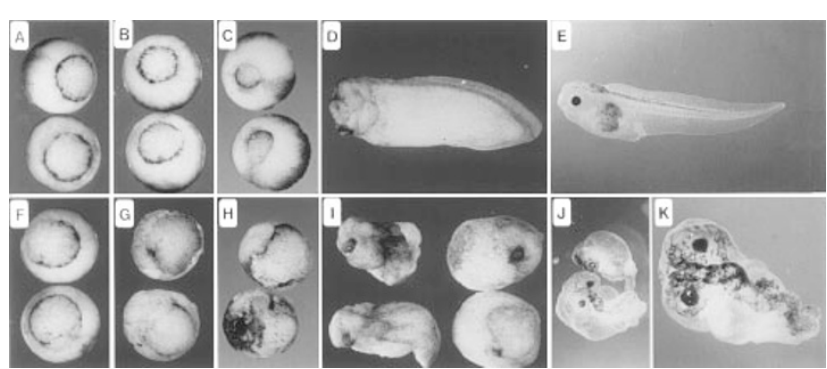

Figure 1 Phenotypic abnormalities caused by Oct-1 constructs. Panels (AE): Normally developing antisense RNA injected embryos of gastrula stages (vegetal views, (A): stage 101/2, (B): stage 111/2, (C): stage 121/2), tailbud stage (D): stage $27-29$, lateral view of embryo oriented with the anterior side to the left), and tadpole stage (E): stage 45 , lateral view of embryo oriented with the anterior side to the left). (F-K): Abnormal embryos injected with Oct-1 PC RNA (see Figure 4A). Full length Oct-1 (NPC) induces a similar phenotype. (F): Vegetal view of gastrula stage $10 \frac{1}{2}$ embryo. Initial gastrulation up to this stage is slightly retarded (blastopore circumference not complete). (G): Vegetal view of gastrula stage $11 \frac{1}{2}$ embryo. Cells dissociate from the dorsal blastopore lip (compare Figure 2). (H): Vegetal view of gastrula stage $12 \frac{1}{2}$ embryo. A large number of detached cells accumulates in the vitelline membrane. (I): Tailbud stage embryos (stages 27-29). The embryos remain in the vitelline membrane, covered by detached cells (embryos on the right). When the vitelline membrane and the dissociated cells are removed, the remainder of the embryo appears to have survived (embryos on the left). ( $\mathbf{J}$ and $\mathbf{K}$ ): Tadpole stage embryos (stage 45). (J) Tail development is severely affected. $\mathbf{K}$ shows an enlargement of an PC RNA injected embryo (dorsal view, anterior side on the left)

LacZ RNA and subsequent $\beta$-galactosidase staining, and by immunohistochemistry (Figure $3 \mathrm{~A}, \mathrm{~B}$ ).

At this point various interpretations were possible, for example the cells that are lost by dissociation at and around the dorsal blastopore lip during the second half of gastrulation, might normally give rise to the posterior part of the embryo, as early involuting cells acquire an anterior specification (Slack and Tannahill, 1992). Alternatively, impaired posterior specification might result in cell dissociation or apoptosis. As a first step to explore several of these possibilities, we characterised the nature of the cell dissociation observed. The experimental data suggested that the cause of cell dissociation might involve programmed cell death (PCD). The dissociated cells exhibit cytoplasmic Oct-1 staining, and the nucleus is not detected in those cases with a DNA binding fluorescent dye (Figures $2 \mathrm{C}$ and $3 \mathrm{~B}$ ). The loss of nuclei is an early event (mid gastrulation stages), and cell lysis is a late (late tailbud stages), apparently secondary, event in affected cells. This sequence of events has been associated with apoptosis in some cell types (Dini et al, 1996). Therefore, the nuclear morphology was studied in antisense and Oct-1 RNA injected gastrula stage embryos (Figure 3). In sense RNA injected embryos, but not in normally developing antisense RNA injected embryos, nuclear condensation and fragmentation was observed in stage 101/2 gastrula stage embryos (Figure 3G). During subsequent development, the nucleus is lost in the absence of cell lysis, and nuclear Oct-1 protein is observed in the cytoplasm (Figure $3 E$ and $H$ ). The temporary absence of Oct-1 staining signals in the fragmented apoptotic nuclei (Figure 3D) probably reflects changes in nucleoprotein organisation and antibody 

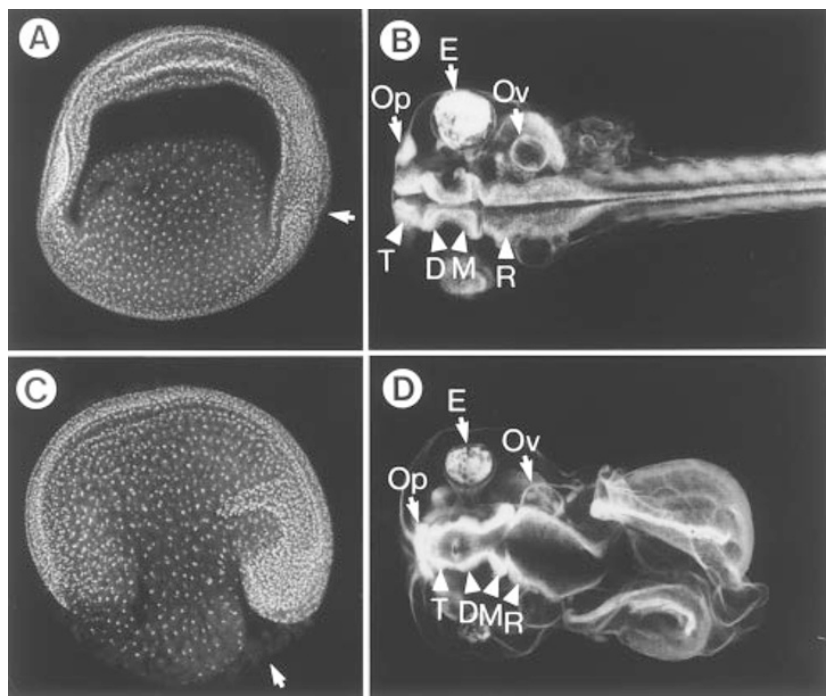

Figure 2 Internal morphology of normal embryos (A and $\mathbf{B})$ and embryos injected with Oct-1 PC RNA (C and D), labelled with BOPRO-3, a DNA binding dye. (A and C) Optical parasagittal sections of gastrula stage (stage 14) embryos. Arrow points to remnant of blastopore and dorsal blastopore lip of respectively a normal and an Oct-1 RNA-injected embryo (posterior side). Note the dissociated cells not reactive with BOPRO-3 (arrow), and the severely disturbed internal gastrulation movements in the PC injected embryo. Blastopore closure is retarded and is in some cases not finished. Neither blastocoel nor archenteron is present. (B and $\mathbf{D}$ ) Projection of optical frontal sections of the dorsal part of tadpole stage (stage 41) embryos. Key to embryonic structures: T, Telencephalon; D, Diencephalon; M, MesencephaIon; R, Rhombencephalon; Op, Olfactory placode; Ov, Otic vesicle. The Oct-1 PC injected embryo shows a strongly reduced, curved, split tail. Anterior structures present in this embryo include telencephalon, diencephalon, mesencephalon, rhombencephalon, eyes, cranial ganglia, otic vesicles, and spinal cord. Note the abnormal and fused olfactory placodes, a retarded development of the brain, and small eyes

accessibility concomitant with nuclear condensation, as the protein is easily detected in the cytoplasm once the nucleus is lost (Figure 3E and $\mathrm{H}$ ). Concordant with the dissociating cells being apoptotic, both in situ TUNEL (TdT-mediated dUTP nick end labelling) analysis, and cell death ELISA experiments indicated increased levels of PCD in Oct-1 overexpressing cells.

\section{Oct-1-induced apoptosis is not caused by perturbed gastrulation and is rescued by non-overexpressing cells}

We characterised the specificity of the Oct-1-induced phenotype in more detail. Cleavage and the initiation of gastrulation proceed normally (Figure 1). Therefore, Oct-1 DNA binding activity was examined in blastula stage extracts of Oct-1 RNA injected embryos. Though it is not causing any effect or perturbation, ectopic Oct-1 appears to be abundantly present already at the blastula stage (gel shift analysis, data not shown). In addition to the antisense RNA control, which is inert in the Xenopus embryo, we have found that some Oct-1 deletion mutants do not cause apoptosis (Figure 5); one of these (designated Oct-1 NP) binds DNA and contains a well documented (Tanaka and Herr, 1990, 1994; Seipel et al,
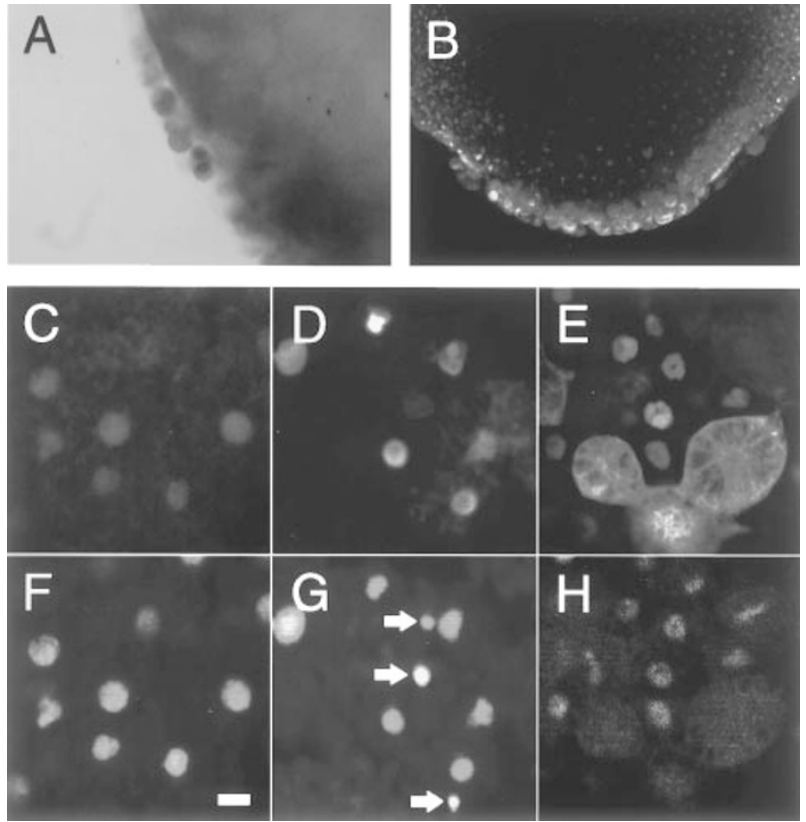

Figure 3 Oct-1 induces nuclear condensation and fragmentation. (A): Embryos were co-injected with LacZ RNA and Oct-1 RNA, and the embryos (stage 121/2) were subjected to $\beta$-galactosidase staining. The dissociated cells contain $\beta$-galactosidase. (B) The dissociated cells contain Oct-1 protein as detected by immunohistochemistry. (C-E) Oct-1 protein as detected by immunohistochemistry in a normal (antisense RNA injected) gastrula stage 101/2 embryo (C), Oct-1 PC RNA injected St. 101/2 embryo (D), and Oct-1 PC RNA injected St. $12 \frac{1}{2}$ embryo (E). The recording settings were different for $\mathbf{C}$ because of the relatively low levels of endogenous Oct-1 protein present in the embryo. ( $\mathbf{F}-\mathbf{H})$ Nuclear morphology as observed by labelling with the DNA binding dye BOPRO-3. DNA- and Oct-1 labelling were performed simultaneously (compare $\mathbf{C}-\mathbf{E}$ with $\mathbf{F}-\mathbf{H}$ ). Bar in F: $10 \mu \mathrm{m}$. Arrows in $\mathbf{G}$ : highly condensed DNA

1992; Tanaka et al, 1992; Das et al, 1995) N-terminal trans-activation domain.

We also addressed the possibility that apoptosis results from nonspecific perturbation of gastrulation. If this were the case, the prediction would be that unhealthy embryos, showing spontaneous gastrulation defects, show increased levels of PCD. This, however, is not the case. Though cells indeed detach from these embryos, these defects are not accompanied by increased levels of apoptosis (Figure 4A), indicating that eventual cell death or necrosis later on in development is not a primary, but rather an indirect effect. The specificity of this early apoptosis observed here implies that perturbed gastrulation and cell dissociation not necessarily cause apoptosis, and the Oct-1-induced gastrulation phenotype might be caused by (rather than being causal for) PCD.

Neither the injected RNA nor its encoded product are toxic by itself, because if the amount of RNA ( 0.3 fmole) that causes a significant increase of cell death when injected in the one-cell zygote, is injected into a single blastomere of the 8-cell stage embryo, no increased cell death is observed, as shown with cell death ELISA (Figure 4B) and in situ TUNEL experiments (data not shown). Apparently Oct-1-induced cell death is rescued by the presence of cells that do not overexpress Oct-1, and Oct-1 
overexpression is not sufficient to induce PCD in a cellautonomous manner. Micro-injection of RNA into two bilateral blastomeres of the 8-cell stage embryo does moderately increase programmed cell death in some embryos as detected by in situ TUNEL analysis (data not shown), in contrast to injections into only one blastomere. The most straightforward interpretation is that Oct-1 down

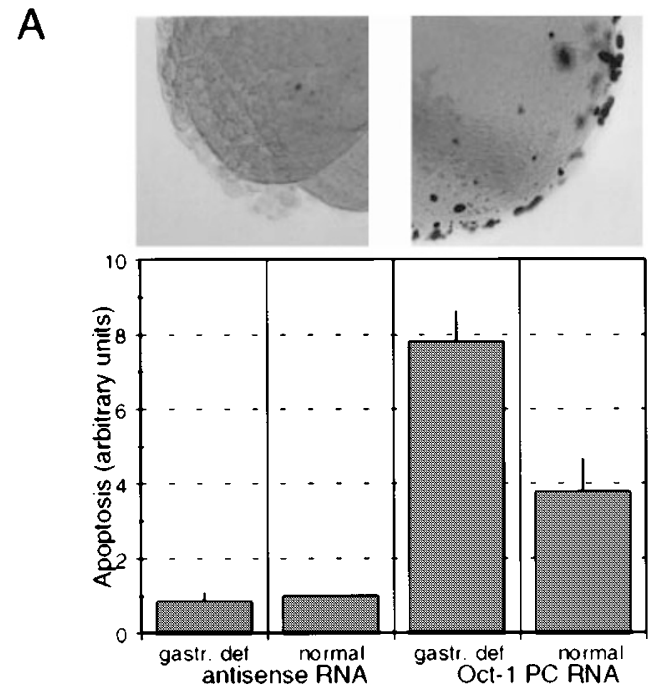

B

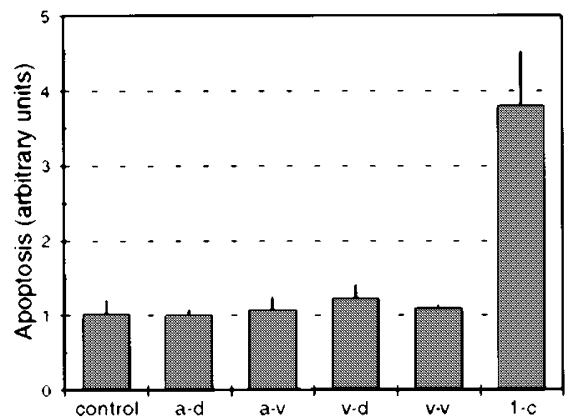

Figure 4 (A) Spontaneous gastrulation defects are not associated with increased PCD. Cell death was assayed by in situ Tdt-mediated dUtp nick end labelling (TUNEL) labelling (A, left and right inset) and with an ELISA assay that detects low molecular weight nucleosomal DNA in cytoplasmic extracts (A, below inset). Gastrula stage embryos, injected at the one-cell stage with 0.3 fmole of either antisense RNA or Oct-1 PC RNA, from both normal batches and from batches exhibiting spontaneous gastrulation defects, were subjected to these techniques. Embryos derived from batches exhibiting spontaneous gastrulation defects show no increase in PCD when injected with antisense RNA (first bar and upper left inset, note dissociated cells in the absence of TUNEL staining) when compared to antisense RNA injected embryos derived from healthy batches (second bar). Unhealthy embryos show a decreased ability to rescue Oct-1-induced effects (third en fourth bar) concordant with a decreased number of cells contributing to secretion of a putative rescuing signalling factor $(\mathbf{B})$. Cell death ELISA was applied to stage $12^{1 / 2}$ embryo extracts, upper panel left represents an antisense RNA injected stage 101/2 embryo from a batch showing spontaneous gastrulation defects, upper panel right represents a stage $12 \frac{1}{2}$ Oct-1 PC RNA injected embryo from a normal batch. (B) Oct-1-induced PCD is rescued by non-expressing cells. Oct-1 PC RNA ( $0.3 \mathrm{fmole})$ was injected into one-cell zygotes and into one blastomere of 8-cell morula embryos. The extent to which PCD was induced was determined at stage $12 \frac{1}{2}$ by cell death ELISA. a-d, animal-dorsal; a-v, animal-ventral; $v-d$, vegetal-dorsal; v-v, vegetal-ventral; 1-c, one cell stage embryo regulates a secreted signal, which then, in the absence of cells providing the signal, causes PCD.

\section{Oct-1 domains that cause posterior deletions}

In order to identify the Oct-1 domains that mediate the functional interactions that disturb embryonic development, a series of Oct-1 variants was constructed by deleting the $\mathrm{N}$ terminal domain, or the C-terminal domain, or both (Figure $5 \mathrm{~A})$. These Oct-1 variant proteins were expressed in Xenopus embryos by injection of equimolar amounts of in vitro synthesised capped RNA into zygotes. The relative abun-

A B
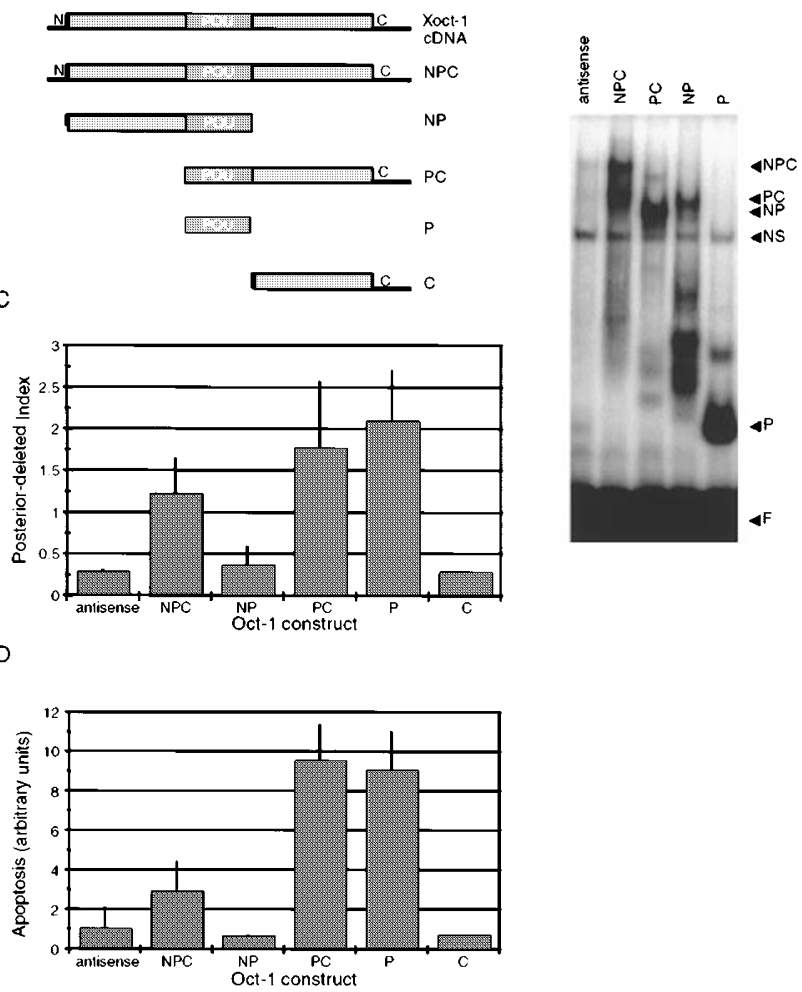

Figure 5 Oct-1 domains in PCD and posterior deletions. (A) Graphic representation of Oct-1 and Oct-1 variants constructed by deleting one or more domains. Full length Oct-1 is referred to as NPC; RNA encoding Oct-1 NPC does not contain the Oct-1 5' UTR present in the cDNA. Oct-1 variants are referred to as NP, $\mathrm{PC}$ and $\mathrm{P}$, according to the domains which are present in the respective construct: the $\mathrm{N}$-terminal activation domain $(\mathrm{N})$, the POU domain (P), and/or the C-terminal activation domain (C). (B) Expression of Oct-1 variants following microinjection of $1.5 \mathrm{fmole}$ of the respective RNA into zygotes. The electrophoretic mobility shift assay with labelled octamer probe reveals octamer binding activity in extracts of gastrula stage (stage 12) embryos. Lanes 1-5: Extracts of embryos injected in the one cell stage with respectively antisense RNA, NPC RNA, NP RNA, PC RNA, and P RNA. The levels of DNA binding competent Oct-1 variant protein, following injection of $0.75 \mathrm{fmole}$ of the respective RNA, relative to endogenous Oct-1, were as follows: antisense: 1.0 (=endogenous protein), NPC: 7.6 (=endogenous plus overexpressed protein), NP: 36, PC: 7.0, P: 73. The different levels of DNA binding competent protein following injection of equimolar amounts of RNA, may reflect intrinsic properties of translation efficiency or stability of the RNA (C) Average posterior-deleted index (PI, see text) of embryos injected with the indicated RNA (standard deviations indicated). (D) The induction of apoptosis following injection with the indicated RNA, as quantified with cell death ELISA 
dance of DNA binding competent protein was determined by electrophoretic mobility shift assays (Figure 5B).

To compare the ability of Oct-1 variants to induce posterior truncations, embryos injected with equimolar amounts of RNA encoding these variant proteins, were classified using a Posterior-deleted Index, which is a modified Head-Tail Index (A.J. Durston, personal communication). In this Posterior-deleted Index (PI), normal embryos are classified as 0 . Embryos which are only slightly curved are also classified as normal, since a slight curvature is often an injection artefact. Embryos with a reduced, but morphologically normal tail, embryos with a strongly curved, or U-shaped tail of normal length, and embryos with a reduced, split tail, are classified as PI 1. Embryos with a curled tail exhibiting severe lateral tissue deletions, and embryos with a rudimentary tail are classified as PI 2. Embryos in which both posterior and anterior structures are affected, are classified as $\mathrm{PI} 3$, since a lack of anterior structures represents the most severe posterior truncation possible.

RNA was injected at doses of $0.3,0.75$, and 1.5 fmole per embryo, and embryonic phenotypes were classified with the Posterior-deleted Index as detailed above (see Figure 5 and Table 1). Injection of antisense RNA does not perturb development (average $\mathrm{PI}=0.3$ at 1.5 fmole $\mathrm{RNA}$, see Figure $5 \mathrm{C})$, as expected, since this RNA does not change the amount of endogenous DNA binding competent Oct-1 (data not shown). NPC Oct-1 causes a significant increase in the average PI (Figure 5C). NP, in contrast to NPC, does not induce phenotypic deletions, although NP is expressed at higher levels than NPC (Figure 5B). In contrast, Oct-1 PC readily induces posterior truncations, although it is less well expressed compared to NP. Embryos are more sensitive to Oct-1 PC than to Oct-1 NPC; although protein levels are similar under these conditions, PC induces more severe phenotypes. Furthermore, at 0.75 fmole RNA per embryo and at smaller amounts of RNA per embryo, the ability to induce phenotypic aberrations is much lower for NPC than for PC (Table 1 and data not shown). Expression of the POU domain alone $(P)$ also induces posterior defects (Figure $5 \mathrm{C}$ ). $P$ protein, however, is relatively abundant under these conditions (Figure 5B), and at RNA doses lower than 0.75 fmole per embryo, $P$ does not show effects on embryonic development, while PC does (data not shown), indicating that embryos are more responsive to $\mathrm{PC}$ than to $P$.
We examined whether the Oct-1 DNA binding domain, the POU domain, is required for phenotype induction. Injections of RNA encoding the $\mathrm{N}$-terminal domain alone (N), did not increase the PI (data not shown), similar to the result obtained with injections of Oct-1 NP RNA. If, however, the induction of phenotypic alterations was induced via a DNA binding independent mechanism, the C-terminal activation domain alone (C) might possess part of the activity of $P C$, like $P$ contains part of the activity of PC. Injection of C RNA, however, does not result in an increased Posterior-deleted Index (Figure 5C).

The relative contribution of Oct-1 domains to the induction of apoptosis as detected by the presence of low molecular weight nucleosomal DNA in the cytoplasm during gastrulation, yielded similar results. Cytoplasmic extracts of gastrula stage $101 / 2$ and stage 12 embryos were tested using a sandwich ELISA with anti-histone and anti-DNA antibodies. Nucleosomal DNA is detected in the cytoplasm of stage 12 embryos expressing Oct-1 NPC, PC or P. In contrast, antisense $\mathrm{RNa}$, Oct-1 NP and $\mathrm{C}$ do not induce apoptosis in gastrulating Xenopus embryos (Figure 5D). The extent to which apoptosis is induced correlates tightly with the average Posterior-deleted Index of embryos injected with the respective RNA (Figure 5C and D).

In conclusion, embryonic cells are most responsive to Oct1 PC, to a lesser degree to Oct-1 P and NPC, and under the conditions tested, the cells are not responsive to antisense RNA, Oct-1 NP, or C. Therefore, the cell death and increased $\mathrm{PI}$ caused by Oct-1 are critically dependent on the POU domain, whereas the $\mathrm{C}$-terminal and $\mathrm{N}$-terminal activation domains respectively contribute to and inhibit programmed cell death and the loss of posterior structures when fused to the POU domain. These data identify the Oct-1 domains that contain the relevant information interfaces for selective protein-DNA and protein-protein contacts on the target promoters that are involved.

\section{Spatio-temporal pattern of endogenous and Oct-1-induced cell death}

To explore the potential relationship between the Oct-1induced PCD and the endogenous death programme, we characterised the spatio-temporal PCD pattern in normal and Oct-1-injected embryos by in situ TUNEL analysis. As assessed with this technique, endogenous programmed cell

Table 1 Phenotypes induced by OCT-1 variants, expressed as percentage of tailbud embryos (stage 33-36) classified with Posterior-deleted Index 0 (normal) - 3 (most severe posterior truncation). Class 'Other' includes dead embryos. Figures represent average percentages (italics) of two independent experiements (total number of embryos: Total \#). Averages and standard errors are represented in Figure $5 \mathrm{C}$

Oct-1 Phenotype induced by 0.75 fmole RNA Phenotype induced by 1.5 fmole RNA

\begin{tabular}{|c|c|c|c|c|c|c|c|c|c|c|c|c|}
\hline RNA & 0 & 1 & 2 & 3 & Other & Total $\#^{a}$ & 0 & 1 & 2 & 3 & Other & Total $\#^{a}$ \\
\hline Antisense & 82 & 10 & 0 & 5 & 3 & 60 & 76 & 17 & 0 & 3 & 3 & 58 \\
\hline$N P C$ & 11 & 50 & 23 & 16 & 0 & 56 & 2 & 76 & 13 & 5 & 5 & 62 \\
\hline$N P$ & 78 & 14 & 7 & 2 & 0 & 58 & 72 & 16 & 7 & 2 & 4 & 57 \\
\hline$P C$ & 24 & 14 & 43 & 16 & 3 & 37 & 0 & 47 & 18 & 25 & 9 & 55 \\
\hline$P$ & 3 & 28 & 45 & 24 & 0 & 58 & 0 & 22 & 47 & 30 & 2 & 60 \\
\hline$C$ & 58 & 8 & 21 & 8 & 4 & 24 & 71 & 21 & 3 & 0 & 6 & 68 \\
\hline
\end{tabular}

${ }^{a}$ Number of embryos corresponding to $100 \%$ 
death appears between stage 10 and 11 in a scattered pattern in epidermal ectoderm, whereas neurectoderm, mesoderm or endoderm show negative (Figure 6A, B). Apoptosis-positive cells are identified as cells with nuclear or cytoplasmic staining; these differently labelled cells represent respectively early and progressed stages of cell death and nuclear degradation. The number of apoptosis-positive cells increases during gastrulation, then remains constant until tailbud developmental stages (Figure 6C), after which the apoptotic rate increases dramatically (data not shown). The primary target of apoptosis during early Xenopus development apparently is the epidermis, like it is in Drosophila (Abrams et al, 1993). During later development, cells in other tissues of the embryo, including the somites and the central nervous system, start to undergo apoptosis (not shown, compare Chen et al (1994); Blaschke et al (1996)).

Oct-1 overexpression induces ectopic programmed cell death near the blastopore in meso- and endoderm, and increases the number of apoptotic cells in ectoderm, concomitant with the appearance of endogenous cell death (Figure 6D-E). Overexpression-induced apoptosispositive cells exhibit cytoplasmic TUNEL staining, indicative of a progressed stage of cell death in stage 10-11 already. The increase of apoptosis following injection of RNA encoding Oct-1 variants (PC and $P$ ) is also detected with in situ TUNEL analysis (data not shown), concordant with the results obtained with the cell death ELISA (Figure 5).
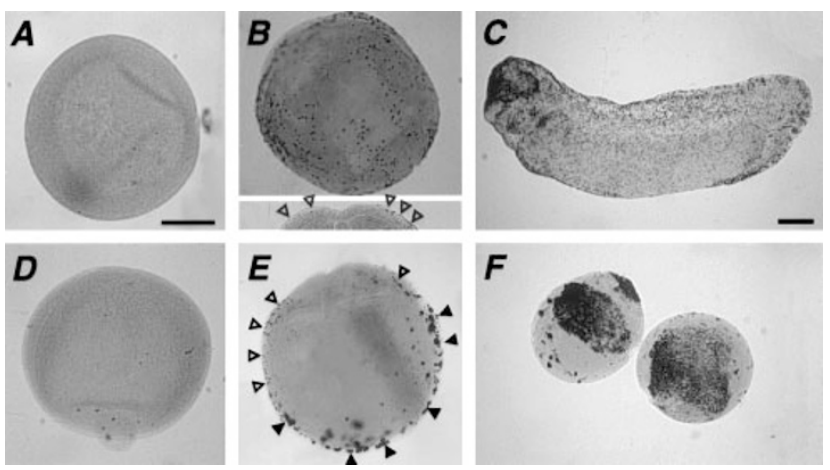

Figure 6 The appearance of endogenous and induced programmed cell death during gastrulation, as assessed with whole mount in situ TUNEL analysis. (A-C): Control embryos. (A): Stage 10 embryo. Incidently, a few apoptosis-positive cells are observed at this stage, indicating that stage 10 is the developmental stage at which the embryonic cell death programme is about to initiate. Bar corresponds to $300 \mu \mathrm{m}$ (the magnification is identical in $\mathbf{A}$, $\mathbf{B}, \mathbf{D}$ and $\mathbf{E})$. (B): Stage 14 embryo, dorsal view, posterior side of the embryo is bottom-right, anterior side is upper-left. Apoptosis is exclusively observed in epidermal ectoderm. Inset panel (B): Transversal view, showing staining in epidermal ectoderm (lateral from midline), whereas the neurectoderm (near midline), the notochord and the somites show negative. (C): Tailbud stage embryo (stage 33), showing staining in epidermis. Lateral view, anterior side to the left. Staining of epidermis only is not due to poor penetration of reagents during the labelling reaction, since broken embryos also do not show labelling in deep tissues (not shown). (D-F): Embryos injected with full length Oct-1 (NPC) RNA (1.5 fmole). (D): Stage 10 embryo. (E): Dorsal view of stage 14 embryo. This embryo shows increased apoptosis in ectoderm, and ectopic cell death in mesoderm and endoderm. Open arrow heads point to cells in which PCD most likely is under the control of the endogenous death programme (compare B), closed arrowheads point to cells undergoing induced PCD. (F) Tailbud stage embryos (stage 33 ), left within the vitelline membrane, to show the detached apoptotic cells (compare Figure 1)
No increase in cell death is observed following injection with antisense or Oct-1 C RNA.

\section{Marker gene expression}

The observation shown in Figure 4B suggests that normal cells secrete a signal which rescues cell death in Oct-1overexpressing cells. Oct-1 overexpression may interfere with this signal, causing cells, in the absence of the signal emanating from neighbouring cells, to undergo PCD. We examined the expression of a series of marker genes in order to characterise the molecular changes brought about by Oct-1 expression.

Brachyury (Xbra) gene expression was examined as a downstream target of FGF signalling (Isaacs et al, 1994). Interestingly, expression of a dominant-negative FGF receptor mutant causes an embryonic phenotype bearing similarity to the Oct-1 phenotype (Amaya et al, 1991). In addition, FGF signalling has been implicated in anteroposterior pattern formation in a pathway that involves Hox genes (Isaacs et al, 1992; Pownall et al, 1996). As shown in Figure 7, Xbra expression is down-regulated in early gastrula stage embryos injected with Oct-1 PC RNA, whereas a small decrease is observed in Oct-1 NPC RNA injected embryos. A number of other genes, including the eFGF, $X R b$ (retino-
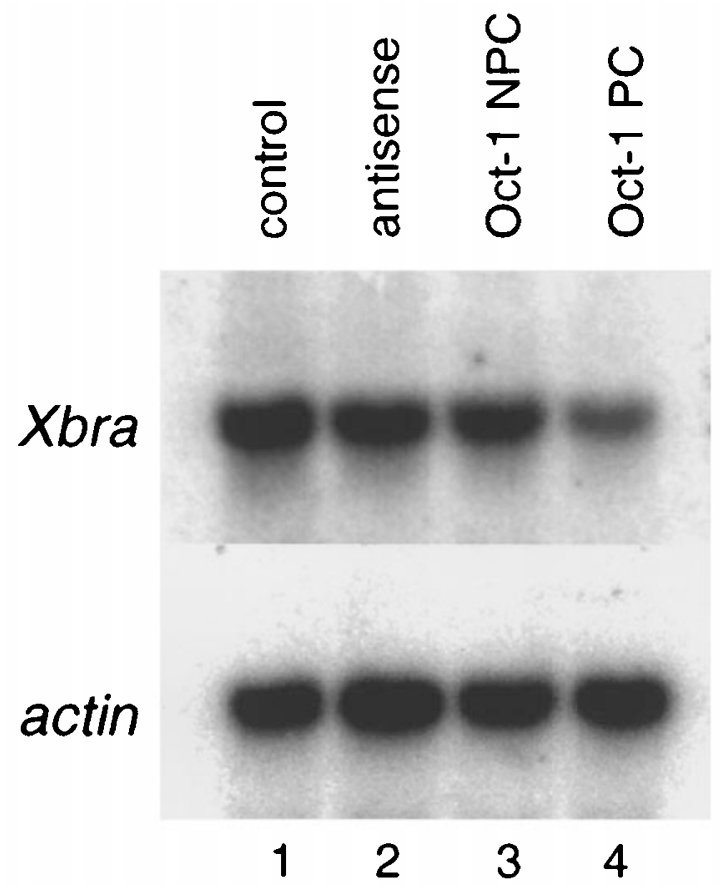

Figure 7 The Xbra gene is down-regulated in Oct-1 injected embryos. RNA was isolated from early gastrula stage (stage 10) embryos that were noninjected (control, lane 1), or injected with 1 fmole of Oct-1 antisense RNA (lane 2), Oct-1 NPC RNA (lane 3), or Oct-1 PC RNA (lane 4). The RNA samples were analyzed by Northern blotting. Actin hybridization serves as RNA loading control. The RNA loading-corrected abundance of Xbra mRNA in Oct-1 NPC and Oct-1 PC RNA injected embryos is respectively $70 \%$ and $32 \%$ relative to that observed in control embryos. The observed effects on Xbra expression are consistent between experiments, and the quantitation is based on two independent sets of injection experiments 
blastoma), Xwnt-5C, and actin genes do not show any change in expression level in these embryos (Figure 7 and data not shown). This result suggests that FGF-signalling is down-regulated in Oct-1 injected embryos. Importantly, the change in Xbra expression level occurs at a developmental stage at which neither PCD nor any morphological effects are apparent in the embryo.

\section{Discussion}

Oct-1 is known as a widely expressed transcription factor with a role in the regulation of house keeping genes like the histone H2B and snRNA genes (Mattaj et al, 1985; Staudt et al, 1986; Fletcher et al, 1987; LaBella et al, 1988; Sturm et al, 1988; Murphy et al, 1989; Parry et al, 1989; Schöler et al, 1989; Heintz, 1991; Hinkley and Perry, 1991, 1992; Danzeiser et al, 1993; Kambe et al, 1993). Previous work has shown that Oct1 is differentially expressed during early development in a pattern distinct from overall cell density or cell proliferation (Veenstra et al, 1995), prompting us to explore developmental functions of this transcription factor by perturbing its expression. In this paper we present some of the results which, in addition to establishing the early spatio-temporal pattern of endogenous apoptosis in the Xenopus embryo, and assessing Oct-1 activation domain function in vivo, implicate regulated Oct-1 expression in the expression or function of a signalling factor essential for gastrulation. Impaired production of this putative activity results in increased levels of apoptosis and posterior deletions.

\section{Spatio-temporal pattern of endogenous apoptosis in Xenopus}

Recently Stack and Newport reported data that suggest a model in which a functional apoptotic pathway in the early cleaving embryo is suppressed by maternally contributed inhibitors (Stack and Newport, 1997). Experiments in which embryos were treated with hydroxyurea during different time intervals indicated that during an early gastrula transition (EGT) negative regulation of an otherwise default apoptosis pathway is transferred from maternal to zygotic control (Stack and Newport, 1997). This transition coincides with the developmental stage at which we identify the initiation of both endogenous and Oct-1-induced apoptosis. This suggests that the zygotic inhibitors of apoptosis expressed between the midblastula transition (MBT, when zygotic transcription starts) and the EGT are different from, or less abundant than the maternal inhibitors. The early spatio-temporal pattern of endogenous PCD, as established in this report, may well be regulated by the zygotic control mechanism Stack and Newport (1997) identified with hydroxyurea experiments.

\section{Down-regulation of brachyury expression}

Concordant with down-regulation of Xbra transcripts as a key to the developmental effects of Oct-1 overexpression are the similar morphological effects of dominant-negative FGF receptor (XFD) expression (Amaya et al, 1991). XFDexpressing embryos exhibit a normal onset of gastrulation, but fail to complete gastrulation normally. The dorsal axis does not form normally resulting in dorsally bent embryos (compare Figure 1J). Embryos at tadpole stages have heads but little or no tail (compare Figure 1K). The dominantnegative FGF receptor appears to interfere with the formation of posterior and lateral mesoderm (Amaya et al, 1991). One of the FGFs expressed in the early Xenopus embryo, eFGF, upregulates Xbra expression (Isaacs et al, 1994), and is involved in a molecular pathway that establishes the antero posterior axis, which also involves $X$ cad 3 and Hox genes (Pownall et al, 1996).

Whereas the whole embryo and individual blastomere injections excluded a cell-autonomous mechanism underlying the effects brought about by Oct-1 overexpression, and the down-regulation of Xbra expression suggested the involvement of an FGF-type signalling factor, eFGF expression appears to be unaffected (data not shown). One of the hypotheses to test is that Oct-1-induced misexpression of another member of the FGF family of growth factors is involved in down-regulation of Xbra. Future studies will address the identify of the signalling activity down-regulated by Oct-1 in our studies, and the mechanism underlying the developmental effects.

Octamer binding transcription factors are known to interact with the HMG box factor Sox2 on the FGF-4 enhancer of the mouse (Dailey et al, 1994; Yuan et al, 1995). Neither Sox2 nor Oct-1 or Oct-3 can activate this enhancer on its own. The cooperative binding of Sox2 and Oct-3 results in synergistic activation of the FGF-4 gene, whereas the Sox2-Oct-1 combination does not activiate. Oct-1 may therefore downregulate the enhancer by competition with Oct-3 for cooperative Sox2-enhancer binding. If these interactions operate on a homologous enhancer in Xenopus, this would provide a mechanism for the non-cell autonomous induction of apoptosis and down-regulation of Xbra in Oct-1 RNA injected embryos. Though it is clear that Oct- 1 inhibits the expression or function of a signalling factor that is required for Xbra expression, it is not clear to what extent other POU domain transcription factors are capable to exert the same (or opposite) effects. The in vivo regulation may depend on a variety of transcription factors that compete for cis-acting elements and that together orchestrate the spatio-temporal expression pattern of the target genes (see for review Veenstra et al (1997)).

\section{Oct-1 interaction interfaces mediating an apoptotic response and Xbra down-regulation}

We have observed unique functions for the Oct-1 activation domains; whereas the C-terminal activation domain contributes to the POU domain's ability to induce apoptosis and posterior deletions, the $\mathrm{N}$-terminal activation domain fails and rather inhibits the POU domain's ability to do so (Figure 5). Both the N-terminal and C-terminal domains of human Oct-1 contain well defined trans-activation domains (Tanaka and Herr, 1990; Seipel et al, 1992; Tanaka et al, 1992; Das et al, 1995). We have tested the highly homologous $\mathrm{N}$-terminal and C-terminal activation domains of Xenopus Oct-1 for activation properties. Both activation domains are capable of activating the Xenopus snail promoter, as tested by co-injecting RNA encoding the Oct-1 deletion variants with snail promoter 
reporter constructs (data not shown). It is well-known though, that the relative activation properties of Oct-1's $\mathrm{N}$ - and $\mathrm{C}$ terminal domains are highly promoter-context dependent. For example, the $\mathrm{N}$-terminal trans-activation domains of Oct-1 and Oct-2 can functionally replace one another when tested on the $\beta$-globin promoter. However, an Oct-2 C-terminal transactivation domain is required together with either one of these $\mathrm{N}$-terminal domains to activate this promoter (Tanaka and Herr, 1990). In contrast, activation of the U2 snRNA promoter requires an Oct-1 C-terminal domain-type activation domain; Oct-2 cannot activate this promoter because of its different $\mathrm{C}$ terminal activation domain (Tanaka et al, 1992). In the context of another promoter, that of the thyrotropin (TSH) $\beta$ gene, the C-terminal domain of Oct-1 exhibits silencing activity (Kim et al, 1996). In addition to serving as a DNA binding domain, the $\mathrm{POU}$ domain has been reported to mediate protein-protein interactions (LeBowitz et al, 1989; Ingraham et al, 1990; Verrijzer et al, 1992; Zwilling et al, 1994, 1995; Bach et al, 1995; Gstaiger et al, 1995; Leger et al, 1995; Luo and Roeder, 1995; Strubin et al, 1995), and in a number of cases the POU domain alone suffices for trans-activation (Murphy et al, 1992; Tanaka et al, 1992; Luo and Roeder, 1995; Mittal et al, 1996). In conclusion, which Oct-1 domains contribute to a certain transcriptional response is highly dependent on the context of the promoter mediating that response. As far as the induction of apoptosis and posterior deletions in the embryo are concerned, the POU domain and the C-terminal activation domain appear to provide the interaction interfaces that mediate these in vivo effects.

\section{Differential expression and protein-protein interactions as a key to developmental control of gene expression}

Whereas future experiments need to characterise the molecular basis of the developmental effects brought about by Oct-1, it is clear from both expression data and functional data that Oct-1 function is not merely restricted to house keeping gene regulation. Conceptually, there are two mechanisms by which a widely expressed transcription factor like Oct-1 contributes to developmental gene regulation: differential expression and protein-protein interactions. In Xenopus embryos, Oct-1 protein levels differ at least sixfold between cells in different parts of the embryo (Veenstra et al, 1995). In addition, protein-protein interactions often provide a major key to establishing cell type-specific expression patterns during embryonic development (Goodrich et al, 1996; Gray and Levine, 1996; Hanna-Rose and Hansen, 1996). For example, protein-protein interactions mediated by POU domain proteins lead to either synergistic activation or transcriptional repression of target genes in cells where the interacting transcription factors are co-expressed. In either case, these interactions contribute to establishing spatially restricted patterns of gene expression (reviewed in Veenstra et al (1997)). The fact that cell type-specific expression of many genes is determined by the relative abundance of transcriptional activators and repressors, and by promoterselective protein-protein interactions mediated by these regulators, explains that, in some cases, target genes are spatially more confined in their expression than the regulators that confer this spatial restriction of expression. Furthermore, it provides a mechanism for the appearance of increasingly specialised programmes of gene expression that are established concomitant with successive induction and differentiation events during embryonic development. It, moreover, may provide a solid conceptual basis to explain specialised developmental roles played by widely but differentially expressed transcriptional regulators such as Oct-1. We anticipate that identification of the putative downregulated FGF factor, and elucidation of the mechanism of its regulation by Oct-1 and other octamer factors, will reinforce the complexity of the spatio-temporal control of gene expression in the embryo.

\section{Materials and Methods}

\section{Constructs and RNA synthesis}

Capped RNAs were synthesised from $3^{\prime}$ linearised pT7TS-derived Oct-1 constructs (pTO constructs) using an in vitro RNA synthesis kit (Ambion). pT7TS was kindly provided by Dr. P. Krieg. PTO-NPC was obtained by cutting pLLB/XOct1 (Veenstra et al, 1995) with Hindlll and EcoRI, filling in the sticky ends of the 2550 bp Oct- 1 fragment, and ligation of this fragment in the EcoRV site of pT7TS. This cloning procedure also yielded a pT7TS construct containing the NPC insert in the reverse orientation. The latter construct was used for synthesis of antisense RNA. The other PTO constructs were constructed using standard procedures with ATG start codons naturally occurring in the Oct-1 cDNA, except in the pTO-P and pTO-PC constructs where an ATG start codon was introduced by PCR.

\section{Microinjection}

RNA was injected in fertilised dejellied eggs at equimolar amounts. 0.75 fmole RNA corresponds to respectively $703 \mathrm{pg}$ antisense RNA, 703 pg NPC RNA, 418 pg NP RNA, 510 pg PC RNA, 215 pg P RNA, $405 \mathrm{pg} C$ RNA. For promoter analysis, $50 \mathrm{pg}$ pXSna-Luc and $50 \mathrm{pg}$ $\beta$-actin-CAT (Schoorlemmer et al, 1994), and 0.75 fmole Oct-1 RNA was co-injected. In most experiments, injections were made in the animal half of the embryo during the first cell cycle of the embryo. Embryos were injected in 3\% ficoll in 25\% MMR buffer (Peng, 1991), which was replaced by $25 \%$ MMR buffer at stage six of development. Embryos were incubated overnight at $14^{\circ} \mathrm{C}$ or $17^{\circ} \mathrm{C}$ depending on the required stage of analysis. LacZ RNA injected embryos were assayed for $\beta$-galactosidase activity as described (Koster et al, 1996).

\section{Electrophoretic mobility shift assays (EMSA)}

EMSA experiments were performed as described before (Veenstra et al, 1995). Briefly, 10-20 embryos were homogenised in 20-40 $\mu \mathrm{l}$ whole cell extract buffer (WCE buffer: $25 \mathrm{mM}$ Tris- $\mathrm{HCl}$ pH 8, $400 \mathrm{mM}$ $\mathrm{KCl}, 1 \mathrm{mM}$ EDTA, $20 \%$ glycerol, $5 \mathrm{mM}$ DTT, $1 \mu \mathrm{g} \mathrm{ml}^{-1}$ pepstatin, $1 \mu \mathrm{g} \mathrm{ml}^{-1}$ leupeptin). $2 \mu$ l of extract was incubated with a 19 base pair ${ }^{32} \mathrm{P}$-end-labelled double stranded oligonucleotide containing the Ad4 octamer site (Verrijzer et al, 1990), in a $20 \mu \mathrm{l}$ binding reaction as previously described (Veenstra et al, 1995). In case fewer embryo equivalents per reaction were required, the appropriate amount of extract was supplemented with WCE buffer to $2 \mu$ l. The protein-DNA complexes were loaded onto a $6 \%$ non-denaturing polyacrylamide gel. Gels were run for $3 \mathrm{~h}$ at $150 \mathrm{~V}$ at $4^{\circ} \mathrm{C}$, dried under vacuum and subjected to autoradiography. Quantitation of Oct-1/DNA complexes was performed using a Phosphor Imager (Molecular Dynamics). 


\section{Immunohistochemistry and DNA staining}

Albino Xenopus embryos, staged according to Nieuwkoop and Faber (Nieuwkoop and Faber, 1967), were collected and fixed as described (Veenstra et al, 1995). Oct-1 immuno labelling was performed as described (Beumer et al, 1995; Veenstra et al, 1995) using an antimouse antibody conjugated to the fluorescent dye Cy5 (Jackson Immunoresearch Laboratories). Staining of nuclei was performed using the DNA binding fluorescent dye BOPRO-3 (Molecular Probes) diluted 1:1000 (1 mM stock solution) in wash buffer during the first wash following the secondary antibody incubation.

\section{Cell death detection}

For detection of nucleosomal DNA in the cytoplasm of Xenopus embryos, a cell death detection ELISA (Boehringer Mannheim) was used. Cytoplasmic extracts were prepared as follows. Extracts were made of five embryos. The embryos were washed in 25\% MMR buffer (Peng, 1991). Excess buffer was removed, and $50 \mu \mathrm{l}$ incubation buffer (Boehringer) was added. Lysis was obtained by gently pipetting up and down. $10 \mu \mathrm{l}$ of this lysate was diluted with $190 \mu \mathrm{l}$ incubation buffer (Boehringer), and the diluted lysate was incubated for $30 \mathrm{~min}$ on ice. The extracts were subsequently centrifuged for $10 \mathrm{~min}$ at $4^{\circ} \mathrm{C}$ in a bench top eppendorf centrifuge at maximal speed. $160 \mu \mathrm{l}$ of supernatant was removed, carefully avoiding pellet contamination. The ELISA then was performed according to the manufacturer's protocol. In situ TUNEL (Tdt-mediated dUTP nick end labelling) analysis was performed in whole mount essentially as described (Blaschke et al, 1996), with a few adaptations. Briefly, embryos were fixed in $4 \%$ paraformaldehyde, stored in methanol, and rehydrated as described for immunohistochemical procedures (Beumer et al, 1995; Veenstra et al, 1995). Vitelline membranes were either removed before fixation, or carefully pierced with a pair of forceps before starting the reaction. Embryos were incubated for $30 \mathrm{~min}$ in TdT buffer (Life) at room temperature; subsequently the embryos were labelled overnight at room temperature with $150 \mathrm{U} \mathrm{ml}^{-1} \mathrm{TdT}$ (Life) and $0.5 \mu \mathrm{M}$ digoxygenin-labelled dUTP (Boehringer-Mannheim). The reaction was terminated by incubation for two times $1 \mathrm{~h}$ in phosphate buffered saline (PBS) containing $1 \mathrm{mM}$ EDTA, at $65^{\circ} \mathrm{C}$. This was followed by four times $1 \mathrm{~h}$ incubation in PBS at room temperature, and labelling of incorporated digoxygenin using alkaline phosphatase-conjugated anti-digoxygenin Fab fragment, according to established procedures (Harland, 1991). The chromogenic reaction was allowed to continue for 1 to $2 \mathrm{~h}$.

\section{Acknowledgements}

We gratefully acknowledge the helpful comments of Dr. A. Caricasole and L. Zeinstra on apoptosis. We are grateful to D. P.A. Krieg for providing the pT7TS vector, and to Dr. M. Sargent for providing the pMX184* $\beta$-GAL snail promoter construct. We thank Drs. A.J. Durston and T.D. Yager for communicating data prior to publication. We thank W.J. Hage for assistance with the confocal laser scanning microscope, J. Narraway and W. Veringa for animal care, F. Vervoordeldonk and J. Heinen for photographic reproductions. The work described in this paper was supported by a grant from the Dutch organization for Scientific Research (NWO) to OHJD.

\section{References}

Abrams JM, White K, Fessler LI and Steller H (1993) Programmed cell death during Drosophila embryogenesis. Development 117: 29-43
Agarwal VR and Sato SM (1991) XLPOU 1 and XLPOU 2, two novel POU domain genes expressed in the dorsoanterior region of Xenopus embryos. Dev. Biol. 147: $363-373$

Amaya E, Musci TJ and Kirschner M (1991) Expression of a dominant negative mutant of the FGF receptor disrupts mesoderm formation in Xenopus embryos. Cell 66: 257-270

Andersen B and Rosenfeld MG (1994) Pit-1 determines cell types during development of the anterior pituitary gland. J. Biol. Chem. 269: 2933529338

Bach I, Rhodes SJ, Pearse II RV, Heinzel T, Gloss B, Scully KM, Sawchenko PE and Rosenfeld MG (1995) P-Lim, a LIM homeodomain factor, is expressed during pituitary organ and cell commitiment and synergizes with Pit-1. Proc. Natl. Acad. Sci. USA 92: 2720-2724

Beumer TL, Veenstra GJC, Hage WJ and Destrée OHJ (1995) Whole mount immunohistochemistry on Xenopus embryos using far red fluorescent dyes. Trends Genet. 11: 9

Bhat KM, Poole SJ and Schedl P (1995) The miti-mere anbd pdm1 genes collaborate during specification of the RP2/sib lineage in Drosophilaneurogenesis. Mol. Cell. Biol 15: 4052-4063

Blaschke AJ, Staley K and Chun J (1996) Widespread programmed cell death in proliferative and postmitotic regions of the fetal cerebral cortex. Development 122: $1165-1174$

Chen WS, Manova K, Weinstein DC, Duncan SA, Plump AS, Prezioso VR, Bachvarova RF and Darnell Jr JE (1994) Disruption of the HNF-4 gene, expressed in visceral endoderm, leads to cell death in embryonic ectoderm and impaired gastrulation of mouse embryos. Genes Dev. 8: 2466-2477

Corcoran LM, Karvelas M, Nossal GJV, Ye Z-S, Jacks T and Baltimore D (1993) Oct2 , although not required for early B-cell development, is critical for later B-cell maturation and for postnatal survival. Genes Dev. 7: 570-582

Dailey L, Yuan H and Basilico C (1994) Interaction between a novel F9-specific factor and octamer-binding proteins is required for cell-type-restricted activity of the fibroblast growth factor 4 enhancer. Mol. Cell. Biol. 14: $7758-7769$

Danzeiser DA, Urso O and Kunkel GR (1993) Functional characterization of elements in a human U6 small nuclear RNA gene distal control region. Mol. Cell. Biol. 13: 4670-4678

Das G, Hinkley CS and Herr W (1995) Basal promoter elements as a selective determinant of transcriptional activator function. Nature 374: 657-660

Dini L, Coppola S, Ruzittu MT and Ghibelli L (1996) Multiple pathways for apoptotic nuclear fragmentation. Exp. Cell Res. 223: 340-347

Finney Mand Ruvkun G(1990) The unc-86gene product couples cell lineage and cell identity in C. elegans. Cell 63: 895-905

Fletcher C, Heintz N and Roeder RG (1987) Purification and characterization of OTF1 , a transcription factor regulating cell cycle expression of a human histone $\mathrm{H} 2 \mathrm{~b}$ gene. Cell 51: $773-781$

Frank D and Harland RM (1992) Localized expression of a Xenopus POU gene depends on cell-autonomous transcriptional activation and induction-dependent inactivation. Development 115: 439-448

Fujii $\mathrm{H}$ and Hamada $\mathrm{H}$ (1993) A CNS-specific POU transcription factor, Brn-2, is required for establishing mammalian neural cell lineages. Neuron 11: 11971206

Goodrich JA, Cutler G and Tjian R (1996) Contacts in context: promoter specificity and macromolecular interactions in transcription. Cell 84: 825-830

Gray S and Levine M (1996) Transcriptional repression in development. Curr. Opin. Cell Biol. 8: 358-364

Gstaiger M, Knoepfel L, Georgiev O, Schaffner W and Hovens CM (1995) A B-cell coactivator of octamer-binding transcription factors. Nature 373 : $360-362$

Hanna-Rose W and Hansen U (1996) Active repression mechanisms of eukaryotic transcription repressors. Trends Genet. 12: 229-234

Harland RM (1991) In Kay BK and Peng HB (eds.), Methods in Cell Biology, Xenopus laevis: practical uses in cell and molecular biology, vol.36. Academic Press Inc., San Diego, pp. 685-695

Harrison SC (1991) A structural taxonomy of DNA-binding domains. Nature 353: $715-719$

Hatzopoulos AK, Stoykova AS, Erselius JR, Goulding M, Neuman T and Gruss P (1990) Structure and expression of the mouse Oct2a and Oct2b, two differentially spliced products of the same gene. Development 109: 349-362 
He X, Treacy MN, Simmons DM, Ingraham HA, Swanson LW and Rosenfeld MG (1989) Expression of a large family of POU-domain regulatory genes in mammalian brain development. Nature 340: 35-42

Heintz N (1991) The regulation of histone gene expression during the cell cycle. Biochim. Biophys. Acta 1088: $327-339$

Herr W and Cleary MA (1995) The POU domain: versatility in transcriptional regulation by a flexible two-in-one DNA-binding domain. Genes Dev. 9: 1679 1693

Herr W, Sturm RA, Clerc RG, Corcoran LM, Baltimore D, Sharp PA, Ingraham HA, Rosenfeld MG, Finney M, Ruvkun G and Horvitz HR (1988) The POU domain: a large conserved region in the mammalian pit-1, oct-1, oct-2, and Caenorhabditis elegans unc-86 gene products. Genes Dev. 2: 1513-1516

Hinkley C and Perry M (1991) A variant octamer motif in a Xenopus H2b histone gene promoter is not required for transcription in frog oocytes. Mol. Cell. Biol. 11:641 654

Hinkley C and Perry M (1992) Histone H2b gene transcription during Xenopus early development requires functional cooperation between proteins bound to the CCAAT and octamer motifs. Mol. Cell. Biol. 12: 4400-4411

Ingraham HA, Flynn SE, Voss JW, Albert KR, Kapiloff MS, Wilson L and Rosenfeld MG (1990) The POU-specific domain of Pit-1 is essential for sequence-specific, high affinity DNA binding and DNA-dependent Pit-1-Pit-1 interactions. Cell 61: $1021-1033$

Isaacs HV, Tannahill D and Slack JMW (1992) Expression of a novel FGF in the Xenopus embryo. A new candidate inducing factor for mesoderm formation and anteroposterior specification. Development 114: 711-720

Isaacs HV, Pownall ME and Slack JMW (1994) eFGF regulates Xbra expression during Xenopus gastrulation. EMBO J. 13: 4469-4481

Kambe F, Tsukahara S, Kato T and Seo H (1993) The POU-domain protein Oct-1 is widely expressed in adult rat organs. Biochim. Biophys. Acta 1171: 307-310

Kim MK, Lesoon-Wood LA, Weintraub BD and Chung JH (1996) A soluble transcription factor, Oct-1, is also found in the insoluble nuclear matrix and possesses silencing activity in its alanine-rich domain. Mol. Cell. Biol. 16: 4366 4377

Koster JG, Eizema K, Peterson-Maduro LJ, Stegeman BI and Destrée OHJ (1996) Analysis of Wnt/Engrailed signaling in Xenopus embryos using biolistics. Dev. Biol. 173: 348-352

LaBella F, Sive HL, Roeder RG and Heintz N (1988) Cell-cycle regulation of a human histone $\mathrm{H} 2 \mathrm{~b}$ gene is mediated by the $\mathrm{H} 2 \mathrm{~b}$ subtype-specific consensus element. Genes Dev. 2: 32-39

LeBowitz JH, Clerc RG, Brenowitz M and Sharp PA (1989) The Oct-2 protein binds cooperatively to adjacent octamer sites. Genes Dev. 3: 1625-1638

Leger H, Sock E, Renner K, Grummt F and Wegner M (1995) Functional interaction between the POU domain protein Tst-1/Oct- 6 and the high-mobility-group protein HMG-I/Y. Mol. Cell. Biol. 15: 3738-3747

Luo Y and Roeder RG (1995) Cloning, functional characterization, and mechanism of action of the B-cell-specific transcriptional activator OCA-B. Mol. Cell. Biol. 15: 4115-4124

Mattaj IW, Lienhard S, Jiricny J and De Robertis EM (1995) An enhancer-like sequence within the Xenopus U2 gene promoter facilitates the formation of stable transcription complexes. Nature 316: 163-167

Mitchell PJ and Tjian R (1989) Transcriptional regulation in mammalian cells by sequence-specific DNA binding proteins. Science 245: 371-378

Mittal V, Cleary MA, Herr W and Hernandez N (1996) The Oct-1 POU-specific domain can stimulate small nuclear RNA gene transcription by stabilizing the basal

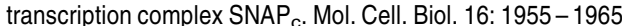

Murphy S, Pierani A, Scheidereit C, Melli M and Roeder RG (1989) Purified octamer binding transcription factors stimulate RNA polymerase III-mediated transcription of the 7SK RNA gene. Cell 59: 1071-1080

Murphy S, Yoon J-B, Gerster T and Roeder RG (1992) Oct-1 and Oct-2 potentiate functional interactions of a transcription factor with the proximal sequence element of small nuclear RNA genes. Mol. Cell. Biol. 12: 3247-3261

Nakai S, Kawano H, Yudate T, Nishi M, Kuno J, Nagata A, Jishage K-i, Hamada H, Fujii H, Kawamura K, Shiba K and Noda T (1995) The POU domain transcription factor Brn-2 is required for the determination of specific neuronal lineages in the hypothalamus of the mouse. Genes Dev. 9: $3109-3121$

Nieuwkoop PD and Faber J (1967) Normal table of Xenopus laevis (Daudin): a systematical and chronological survey of the development from the fertilized egg till the end of metamorphosis, 2nd ed. North Holland Publishing Compnay, Amsterdam
Parry HD, Scherly D and Mattaj IW (1989) 'Snurpogenesis': The transcription and assembly of $U$ snRNP components. Trends Biochem. Sci. 14: 15-19

Peng HB (1991) In Kay BK and Peng HB (eds.), Methods in cell biology: Xenopus laevis, practical uses in cell and molecular biology, vol. 36. Academic Press, Inc., San Diego, California, pp. 657-662

Pownall ME, Tucker AS, Slack JMW and Isaacs HV (1996) eFGF, Xcad3 and Hox genes form a molecular pathway that establishes the anteroposterior axis in Xenopus. Development 122: 3881-3892

Rosenfeld MG (1991) POU-domain transcription factors: pou-er-ful developmental regulators. Genes Dev. 5: 897-907

Rosner MH, Vigano MA, Ozato K, Timmons PM, Poirier F, Rigby PWJ and Staudt LM (1990) A POU-domain transcription factor in early stem cells and germ cells of the mammalian embryo. Nature 345: 686-692

Schöler HR (1991) Octamania: The POU factors in murine development. Trends Genet. 7: 323-329

Schöler HR, Hatzopoulos AK, Balling R, Suzuki N and Gruss P (1989) A family of octamer-specific proteins present during mouse embryogenesis: evidence for germline-specific expression of an Oct factor. EMBO J. 8 2543-2550

Schonemann MD, Ryan AK, McEvilly RJ, O'Connell SM, Arias CA, Kalla KA, Li P, Sawchenko PE and Rosenfeld MG (1995) Development and survival of the endocrine hypothalamus and posterior pituitary gland requires the neuronal POU domain factor Brn-2. Genes Dev. 9: 3122-3135

SchoorlemmerJ, Van PuijenbroekA, Van den Eijnden M, JonkL, Pals C and KruijerW (1994) Characterization of a negative retinoic acid response element in the murine Oct4 promoter. Mol. Cell. Biol. 14: 1122-1136

Seipel K, Georgiev O and Schaffner W (1992) Different activation domains stimulate transcription from remote ('enhancer') and proximal ('promotor') positions. EMBO J. 11: $4961-4968$

Shimazaki T, Okazawa H, Fujii H, Ikeda M, Tamai K, McKay RDG, Muramatsu M and Hamada $\mathrm{H}$ (1993) Hybrid cell extinction and re-expression of Oct-3 function correlates with differentiation potential. EMBO J. 12: 4489-4498

Slack JMW and Tannahill D (1992) Mechanism of anteroposterior axis specification in vertebrates: lessons from the amphibians. Development 114: 285-302

Stack JH and Newport JW (1997) Developmentally regulated activation of apoptosis early in Xenopus gastrulation results in cyclin A degradation during interphase of the cell cycle. Development 124: 3182-3195

Staudt LM, Singh H, Sen R, Wirth T, Sharp PA and Baltimore D (1986) A lymphoidspecific protein binding to the octamer motif of immunoglobulin genes. Nature 323: $640-643$

Strubin M, Newell JW and Matthias P (1995) OBF-1, a novel B cell-specific coactivator that stimulates immunoglobulin promotor activity through association with octamer-binding proteins. Cell 80: 497-506

Sturm RA, Das G and Herr W (1988) The ubiquitous octamer-binding protein Oct-1 contains a POU domain with a homeobox subdomain. Genes Dev. 2: 1582 1599

Suzuki N, Rohdewohld H, Neuman T, Gruss P and Schöler HR (1990) Oct-6: a POU transcription factor expressed in embryonal stem cells and in the developing brain. EMBO J. 9: 3723-3732

Takeda H, Matsuzaki T, Oki T, Miyagawa T and Amanuma H (1994) A novel POU domain gene, zebrafish pou2: expression and roles of two alternatively spliced twin products in early development. Genes Dev. 8: 45-59

Tanaka M and Herr W (1990) Differential transcriptional activation by Oct-1 and Oct2: Interdependent activation domains induce Oct-2 phosphorylation. Cell 60 $375-386$

Tanaka M and Herr W (1994) Reconstitution of transcriptional activation domains by reiteration of short peptide segments reveals the modular organization of a glutamine-rich activation domain. Mol. Cell. Biol. 14: 6056-6067

Tanaka M, Lai J-S and Herr W (1992) Promoter-selective activation domains in Oct-1 and Oct-2 direct differential activation of an snRNA and mRNA promoter. Cell 68 : $755-767$

Veenstra GJC, Beumer TL, Peterson-Maduro J, Stegeman BI, Karg HA, Van der Vliet PC and Destrée OHJ (1995) Dynamic and differential Oct-1 expression during early Xenopus embryogenesis: persistence of Oct-1 protein following downregulation of the RNA. Mech. Dev. 50: 103-117

Veenstra GJC, Van der Vliet PC and Destrée OHJ (1997) POU domain transcription factors in embryonic development. Mol. Biol. Rep. 24: 139-155

Verrijzer CP and Van der VlietPC (1993) POU domain transcription factors. Biochim Biophys. Acta 1173: 1-21 
Verrijzer CP, Kal AJ and Van der Vliet PC (1990) The oct-1 homeo domain contacts only part of the octamer sequence and full oct-1 DNA-binding activity requires the POU-specific domain. Genes Dev. 4: 1964-1974

Verrijzer CP, Van Oosterhout JAWM and Van der Vliet PC (1992) The Oct-1 POU domain mediates interactions between Oct-1 and other POU proteins. Mol. Cell. Biol. 12: $542-551$

Whitfield T, Heasman J and Wylie C (1993) XLPOU-60, a Xenopus POUdomain $\mathrm{mRNA}$, is oocyte-specific from very early stages of oogenesis, and localized to presumptive mesoderm and ectoderm in the blastula. Dev. Biol. 155: $361-370$

Witta SE, Agarwal VR and Sato SM (1995) XIPOU 2, a noggin-inducible gene, has direct neuralizing activity. Development 121: 721-730
Yeo SL, Lloyd A, Kozak K, Dinh A, Dick T, Yang X, Sakonju S and Chia W (1995) On the functional overlap between two Drosophila POU homeo domain genes and the cell fate specification of a CNS neural precursor. Genes Dev. 9: 1223-1236

Yuan H, Corbi N, Basilico C and Dailey L (1995) Developmental-specific activity of the FGF-4 enhancer requires the synergistic action of Sox2 and Oct-3. Genes Dev. 9: $2635-2645$

Zwilling S, Annweiler A and Wirth T (1994) The POU domains of the Oct1 and Oct2 transcription factors mediate specific interaction with TBP. Nucleic Acids Res. 22: $1655-1662$

Zwilling S, König H and Wirth T (1995) High mobility group protein 2 functionally interacts with the POU domains of octamer transcription factors. EMBO J. 14: $1198-1208$ 